Federal Reserve Bank of Minneapolis

Research Department

\title{
Reputation Spillover Across Relationships With Enduring and Transient Benefits: Reviving Reputation Models of Debt
}

\author{
Harold L. Cole and Patrick J. Kehoe*
}

Working Paper 534

August 1994

\begin{abstract}
A traditional explanation for why sovereign governments repay debts is that they want to keep a good reputation so they can easily borrow more. In our model, this explanation does not hold if a government has access to an adequate savings technology, regardless of its past actions. Given such access, governments get only transient benefits from maintaining a good relationship with bankers, and such benefits cannot support borrowing. We argue that if a country is involved in a myriad of different trust relationships, there can be reputation spillover to a nondebt relationship which has enduring benefits. We show that such a spillover can allow a government's reputation to support a large amount of borrowing.
\end{abstract}

*Cole, Federal Reserve Bank of Minneapolis; Kehoe, University of Pennsylvania and Federal Reserve Bank of Minneapolis. The views expressed herein are those of the authors and not necessarily those of the Federal Reserve Bank of Pennsylvania the Federal Reserve System. 
The standard reputation argument for why sovereign governments repay their debts is that governments fear that if they default their tarnished reputations will spill over to future debt relationships and make bankers less willing to lend to them. (See, for example, Jonathan Eaton and Mark Gersovitz 1981; Kletzer 1984; Rodolfo Manuelli 1986; Herschel Grossman and John Van Huyck 1988; Harold Cole, James Dow, and William English 1989; and Andrew Atkeson 1991. ${ }^{1}$ ) Recently, Jeremy Bulow and Kenneth Rogoff (1989b) have challenged this traditional explanation. In a provocative paper, they show that "under fairly general conditions, lending to small countries must be supported by the direct sanctions available to creditors, and cannot be supported by a country's 'reputation for repayment'" $(1989$, p. 43). A key reason for the difference between this result and the results in the rest of the literature is that Bulow and Rogoff assume that, regardless of its past behavior, a government has a means of savings through which it can earn the market rate of return. The rest of the literature, either explicitly or implicitly, assumes that if a country defaults it cannot save.

Bulow and Rogoff conjecture that since countries are involved in a myriad of relationships, reputation may be able to support debt even with their assumption if the analysis is expanded from the partial reputation models where debt is viewed in isolation to a general reputation model that includes all the country's relationships. In this paper, we examine the Bulow-Rogoff conjecture in a model in which misbehavior in the debt arena tarnishes a government's reputation in other areas. We find that whether or not the conjecture holds depends critically on the nature of the other relationship: if it has enduring benefits, it holds: if it has transient benefits, it does not.

To set up our later analysis, we begin by reviewing the Bulow-Rugoff result in a model of a single debt relationship with an infinite horizon and complete information: in any equilibrium, there can be no positive debt. We then examine the conjecture by adding other relationships to the model. We first consider two examples of relationships which have transient benefits in the sense 
that the value to the government of maintaining a good relationship is positive only for a finite amount of time. One example is simply another debt relationship, and the other is an oil relationship in which two countries decide how quickly to exhaust a common resource. Even though reputation can spill over from the debt relationship to these other transient benefit relationships, we show in each example that there is a unique equilibrium with no debt.

We also consider other relationships which have enduring benefits in the sense that no matter what the past history, the future value of maintaining a good relationship is large. The simplest examples of such relationships are repeated relationships in which the per period benefits from maintaining the relationship are constant. For such relationships, the present value of maintaining a good relationship is necessarily large for high discount factors. Of course, there are more elaborate dynamic relationships with physical state variables which also have enduring benefits. We illustrate how differently spillover works when the other relationship is enduring by considering a model with debt and a simple repeated labor relationship. In the model, reputation spillovers support debt in the sense that certain trigger strategies, called spillover strategies, which connect behavior in one relationship to the behavior in the other, are equilibria. These equilibria have positive debt. In this sense, we show the Bulow-Rogoff conjecture holds for certain models.

The model with debt and an enduring relationship is an infinite horizon model. In such a model there are a large number of other equilibria in which such a spillover does not occur and no debt is supported. Of course, one might want to go further and ask if we can construct a model in which this spillover must occur. We think of this exercise as examining what type of model we need for the Bulow-Rogoff type spillover equilibria to be in some sense the "natural" equilibria of the model.

To do so, we consider an incomplete information model with a small amount of uncertainty about whether the government attaches a large disutility to not honoring its contracts. ${ }^{2}$ (For some 
early work in industrial organization using repeated models with incomplete information, see David Kreps and Robert Wilson 1982 or Paul Milgrom and John Roberts 1982.) We find several results. First, for any finite horizon there is an essentially unique equilibrium in which there are spillovers. Moreover, these spillovers are both a natural and necessary consequence of rational inferences made by the private agents. Second, for a sufficiently long horizon, positive debt can be supported in equilibrium. Third, we consider a sequence of finite horizon incomplete information economies with successively longer horizons. We show that both the finite horizon strategies and the equilibria of the incomplete information game converge naturally to the infinite horizon strategies and equilibria of the complete information game. Moreover, these limiting strategies are themselves a legitimate equilibrium to a naturally modified infinite horizon game. Fourth, we show that the same holds true if the uncertainty about the government's type converges to zero at a sufficiently slow rate as the horizon goes to infinity. These results imply that there is both a close and natural connection between the finite horizon incomplete information results and the infinite horizon complete information results. Indeed, we think of these results as providing one possible motivation for focusing on the equilibrium with spillover effects in the infinite horizon model.

Of course, if we add different types of incomplete information, then the spillover equilibrium of the finite horizon model can disappear. Indeed, as is well known, by changing the incomplete information we can support approximations to any of the multitude of equilibria of the infinite horizon model. While this is true, we find our exercise instructive in that it makes clear some of the underlying stories one must tell for the Bulow-Rogoff conjectured equilibria not only to exist but also to be the natural outcomes. We view this as important if we want to go beyond examining the Bulow-Rogoff conjecture and to suggest these general reputation models are interesting positive models of countries' interactions. 


\section{An Economy With a Single Transient Benefit Debt Relationship}

Consider a world economy that consists of two countries. In each period $t=0, \ldots$, the economy has a single good. One country consists of a large number of risk-neutral agents called bankers. Each banker has a discount factor $\beta$ and is endowed with a fixed amount of the good in each period. We assume bankers act competitively. The other country is represented by an agent, called the government, which has access to a country-specific investment project. In each period t, an investment of $x_{t+1}$ units in the project produces output of $A x_{t+1}$ units in period $t+1$. The project has a maximal size of 1 ; thus, $x_{t+1} \leq 1$. Assume that

\section{(1.1) $\beta \mathrm{A}>1$}

so that the project's gross return $A$ is greater than the bankers' discount rate $\rho=1 / \beta$. The government also has access to a saving technology that allows it to earn the world rate of return $\rho$ on its savings. This savings technology can be interpreted either as a domestic technology or as access to the world market for savings. The government has no endowments of the good in any period and zero borrowing or saving at the beginning of period 0 . Thus,

(1.2) $b_{0}=0$

The preferences of the government are given by

$$
\sum_{t=0}^{\infty} \beta^{t} c_{t} .
$$

We will soon consider a model in which the government cannot commit to honoring debt contracts made with the bankers. First, though, we build in some intuition by considering a model in which there is a technology through which the government can commit to honoring its debt. From the linearity of banker preferences and the assumption that they behave competitively, it is clear that 
in each period t the equilibrium gross rate of interest on loans is $1+r_{t}=\rho$. From (1.1), the return on the project, A, is greater than $\rho$, and hence, with such an interest rate in each period it is optimal for the government to borrow so that it can fully fund the project. In period 0 the government borrows 1 , invests it, and consumes nothing. In period 1 and all future periods the government borrows 1 and invests it, repays $\rho$ on the old loan, and consumes output net of repayment, A - $\rho$. The discounted value of utility under commitment is thus

$$
\beta(\mathrm{A}-\rho)+\beta^{2}(\mathrm{~A}-\rho)+\ldots=\frac{\beta(\mathrm{A}-\rho)}{1-\beta}
$$

Of course, given the linear preferences of the government and that the discount factor of the government satisfies $\beta=1 / \rho$, there are a variety of ways the timing of consumption by the government can be structured to yield the same discounted value of utility.

Consider now a model without such a commitment technology. A precise description of the timing of events in the model is as follows. At the beginning of period $t$ there are two state variables: the amount of debt either owed or saved, $\left(1+r_{t}\right) b_{t}$, and the amount of new output, $A x_{t}$. If $b_{1}>0$, the government decides whether to pay the old loan by setting $z_{t}=1$ or to default by setting $\mathrm{z}_{\mathrm{t}}=0$, subject to the constraint

$$
\text { (1.5) } \mathrm{z}_{\mathrm{t}}\left(1+\mathrm{r}_{\mathrm{t}}\right) \mathrm{b}_{\mathrm{t}} \leq \mathrm{Ax}_{\mathrm{t}} \text {. }
$$

If $b_{t}<0$, the government necessarily sets $z_{t}=1,\left(1+r_{t}\right)=\rho$ and the government receives a payment of $\rho \mathrm{b}_{\mathrm{t}}$. Bankers, having seen the default decision, offer the government a new set $\mathrm{S}_{\mathrm{t}+1}$ of loan contracts. Each contract $s_{t+1}$ is a pair $\left(r_{t+1}, b_{t+1}\right)$ which specifies an interest rate $r_{t+1}$ and a loan amount $b_{t+1}$. We also embed the savings possibilities in $S_{t+1}$ by having $S_{t+1}$ include savings contracts which specify $1+r_{t+1}=\rho$ for any $b_{t+1}<0$. The government then chooses some specific contract $s_{t+1}$, how much to consume, $c_{t}$, and how much to invest, $x_{t+1}$, subject to the constraints 
(1.6) $\mathrm{x}_{\mathrm{t}+1} \leq 1$

(1.7) $c_{t}+x_{t+1}-b_{t+1}=A x_{t}-z_{t}\left(1+r_{t}\right) b_{t}$.

We begin by showing that the full commitment allocations cannot be supported as equilibrium allocations. To see this consider these allocations and consider the decision to repay at the end of some period $t \geq 1$. If the government continues with the full commitment policy it gets $\mathbf{A}-\rho$ in all periods. Consider the following deviation. The government defaults at $t$, invests 1 , and consumes $A-1$. In period $t+1$ and all periods thereafter it invests 1 in the project, and consumes $A-1$. Thus, under commitment the government gets $(A-\rho) /(1-\beta)$, while under this deviation it gets $(A-1) /(1-\beta)$. Since $\rho>1$, this deviation is strictly preferred for all discount factors $\beta \in$ $(0,1)$. Thus the full commitment allocations cannot be supported as equilibrium allocations. Note that a similar argument holds for any other allocations which yield the same discounted utility but for which the timing of consumption differs.

The intuition for this result is simply that once the government has one unit on hand it has no need to borrow any more, and thus the value of maintaining a good relationship with the bankers is zero. Moreover, if it breaks this relationship by defaulting, it saves the funds it owed, and thus defaulting dominates maintaining a good relationship. More generally, in the spirit of Bulow and Rogoff (1989b) and Rosenthal (1991) we can show

Proposition 1. In the economy with a debt relationship, the unique equilibrium allocations are the autarky allocations.

The proof is in the appendix. The intuition for this proposition is similar to the intuition for why the full commitment allocations are not supportable as equilibrium allocations. Consider any equilibrium and consider the period in which the present value of debt owed by the government is maximal. Since this value of the debt is the largest it will ever be, this means that in each 
subsequent period the government is, on net, paying back the bankers. If the government instead defaults and invests the funds it would have paid back it can finance its original investment pattern and increase consumption.

Our model works quite differently than does the reputation models of sovereign debt of Eaton and Gersovitz (1981), among others. In those models, trigger strategies, which specify that if the government ever defaults bankers refuse to lend to it from then on, will support positive debt. There are two reason for the difference in results. First, in those models the government had no way to safely save after a default. Second, countries in those models had a recurring need to either borrow or save. In such models if there was no way to save, the debt relationship has enduring benefits: no matter what the past history, the future value of maintaining a good relationship is large. Both of these conditions are necessary for Eaton and Gersovitz result. Even if a country had a recurring need to either borrow or save, Bulow and Rogoff have shown that its ability to safely save abroad undercuts the force of post default borrowing restrictions. Even if the government could not save abroad after defaulting, Rosenthal (1991) has shown that the domestic investment technology may be sufficient to undercut the force of the restrictions on borrowing. To summarize: If a government has some means of transferring resources into the future at a rate that is equivalent to what it could achieve prior to defaulting, then the debt relationship has only transient benefits and it is impossible to support positive debt. If this is not the case, then the debt relationship has enduring benefits and it may be possible to support positive debt.

\section{Spillover With Multiple Relationships}

In this section we add to the model of Section I other relationships that involve trust. We first show that if we add another transient benefit relationship our earlier results are unchanged: no 
positive debt can be supported in equilibrium. We then show that if we add an enduring benefit relationship, large amounts of borrowing can be supported.

\section{A. Adding Other Transient Benefit Relationships}

Consider adding to the Section 2 model another relationship with transient benefits. Clearly the most trivial way is to add another debt relationship with another group of bankers in another country which simply replicates the first. Consider strategies in which a government's misbehavior in one debt relationship spills over to affect its treatment in another debt relationship. Specifically, consider strategies for the bankers which specify that if the government breaks a contract with either group of bankers in either lending country then no banker will lend it any funds again. Faced with such strategies, the government will either simultaneously honor both types of debt contracts or break both since breaking either one causes both groups of bankers to stop lending. A moment's reflection should make it clear that even though there is a spillover across the debt relationships, it is still impossible to support positive debt. Since both the benefits and the losses from defaulting in the model with two projects are simply twice what they are in the model with one project, the default decisions are unchanged. Hence even with spillovers from one debt relationship to another, no positive debt can be supported in equilibrium.

While this first example is useful, it is somewhat special in that the added relationship is totally symmetric to the existing one. It is important to realize that even if misbehavior in the debt relationship spills over to a very different type of relationship, this spillover cannot support debt if this other relationship has transient benefits. To make this point concrete, we consider a relationship which involves the use of an exhaustible resource.

Suppose the borrowing country and some other country (which may or may not be the lending country) can pump oil from a common pool of oil in the ground. Let $Y$ denote the total 
amount of oil in the ground in period 0 . Suppose each country, denoted $i=1,2$, can pump the oil at per period rates of $y_{\mathrm{it}} \in\{0,1,2\}$, interpreted respectively as a zero rate, a slow rate and a fast rate of country $\mathrm{i}$. The technology for pumping oil is such that if the aggregate rate of pumping is too fast, both countries recover a lower fraction of the oil they pump. To capture this in a simple way we suppose that if the aggregate pumping rate is $y_{1 t}+y_{2 t}$, the fraction of oil recovered is

$$
\alpha\left(y_{1 t}+y_{2 t}\right)=\left\{\begin{array}{l}
1 \text { if } y_{1 t}+y_{2 t}<2 \\
\alpha \text { if } y_{1 t}+y_{2 t} \geq 2
\end{array}\right.
$$

where $3 / 4<\alpha<\bar{\alpha}<1$. Thus, if either both countries extract at the high rate or one extracts at the high rate and the other at the other low rate, then the aggregate rate is too fast and for each unit of oil pumped out only the fraction $\alpha$ of each unit of oil is successfully recovered, and the fraction $1-\alpha$ is lost. Now if the aggregate pumping at $t, y_{1 t}+y_{2 \mathfrak{t}}$, does not exhaust the total amount of oil remaining at the beginning of period $t, Y_{t}$, then the oil recovered by country $i$ at $t$ is simply $y_{1 \mathrm{t}} \alpha\left(\mathrm{y}_{1 \mathrm{t}}+\mathrm{y}_{2}\right)$. If the aggregate pumping would exhaust the remaining stock so that $\left(\mathrm{y}_{1 \mathrm{t}}+\mathrm{y}_{2 \mathrm{t}}\right)>\mathrm{Y}_{\mathrm{t}}$ the oil recovered by country $i$ is

$$
\frac{y_{1 t}}{y_{1 t}+y_{2 t}} \alpha\left(y_{1 t}+y_{2 t}\right) Y_{t}
$$

that is, each country recovers an amount proportional to its pumping rate. Let $\alpha\left(\mathrm{y}_{1 \mathrm{t}}+\mathrm{y}_{2 \mathrm{t}} \mid \mathrm{Y}_{\nu}\right)$ denote $\alpha\left(\mathrm{y}_{1 \mathrm{t}}+\mathrm{y}_{2 \nu}\right)$ if the oil is not exhausted, and let it denote $\alpha\left(\mathrm{y}_{\mathrm{It}}+\mathrm{y}_{2 \nu}\right) \mathrm{Y}_{\mathrm{t}} /\left(\mathrm{y}_{1 \mathrm{t}}+\mathrm{y}_{20}\right)$ if it is exhausted.

To see that this relationship has transient benefits, let us consider it in isolation from the debt relationship. The utility of country $i$ is

$$
\sum \beta^{t} \mathrm{y}_{\mathrm{it}} \alpha\left(\mathrm{y}_{1 \mathrm{t}}+\mathrm{y}_{2 \mathrm{t}} \mid \mathrm{Y}\right)
$$

To get some feel for how this model works, suppose for a moment that both countries cooperate and jointly choose symmetric extraction rates of $y_{1 t}=y_{2 t}=y_{t}$ to maximize their utility. If countries 
extract at the slow rate until the oil is exhausted, then each country has a utility of $\Sigma_{t=0}^{\mathbf{T}} \beta^{\mathrm{t}}$. If both extract at the high rate until oil is exhausted, both get utility $2 \alpha \Sigma_{\mathrm{t}=0}^{\mathrm{T} / 2} \beta^{\mathrm{t}}$ where $\mathrm{T}=\mathrm{Y} / 2$, and we assume $\mathrm{Y} / 4$ is an integer. Given the linearity of the model no combination of slow rates and fast rates can do better than either of these two options. Notice that for $\beta$ close to 1 the discounted payoffs are approximately $\mathrm{Y} / 2$ from the slow rate and $\alpha \mathrm{Y} / 2$ from the fast rate. Since $\alpha<\underline{\alpha}<1$, clearly there is some $\underline{\beta}$ close enough to 1 such that for all $\beta \in(\underline{\beta}, 1)$ extracting at slow rate until all the oil is exhausted is the optimal cooperative solution.

Now consider trying to support this cooperative solution when countries noncooperatively choose their extraction rates. Consider first the beginning of period $\mathrm{T}$. There are two barrels of oil left in the ground, so $\mathrm{Y}_{\mathrm{T}}=2$, and both countries are supposed to extract one barrel each. If country $\mathrm{i}$ sticks to this solution, it receives a payoff of 1 while if it deviates to the high rate it receives a payoff of $4 \alpha / 3$. Since $\alpha>3 / 4$, this deviation is preferred. By backward induction it follows the unique noncooperative solution is to extract at the high rate in each period until the oil is exhausted.

Now consider adding this oil relationship to the model with the debt relationship. Consider spillover strategies in which a government's misbehavior in the debt relationship spills over to the oil relationship and vice versa. Specifically, suppose bankers and the government of the other country with oil have strategies which specify that if the borrowing government either breaks a loan contract or pumps oil at the high rate, the bankers will never again lend to it and the government of the other country will pump at the high rate thereafter. Faced with such spillover, the government will either "behave" in both relationships or it will misbehave in both since misbehaving in one ruins the other. It should be clear, however, that since both relationships have transient benefits such strategies cannot support good outcomes. 
Proposition 2. In the economy with the debt and oil relationships the unique equilibrium allocations have no borrowing and countries pump oil at the high rate until it is exhausted.

Proof. Clearly, in any equilibrium oil must be pumped at some date. If not, the argument of Proposition 1 would imply there is no positive debt. But then there would be an incentive for both countries to deviate and pump some oil. Since the stock of oil is finite, in any equilibrium there is some finite date $\mathrm{T}$ at which pumping is positive and zero thereafter. At date $\mathrm{T}$ the argument in the proof of Proposition 1 implies there can be no positive debt from period T onwards. But then this implies that no debt from period $\mathrm{T}-1$ will be repaid in period $\mathrm{T}$ and that pumping will be at the high rate. Anticipating this, lenders at $T-1$ don't lend. By backward induction the equilibrium strategy of the country is to never repay and to pump at the high rate. The equilibrium strategy of the lenders is to never lend. Thus, the unique equilibrium has zero debt and both countries pumping at the high rate until the oil is exhausted.

It is worth pointing out that in an economy with two seperate oil stocks Loury (1990) has shown that it is possible to support a cooperative equilibrium even if the oil stocks are finite.

So far we have given two examples in which spillovers from a debt relationship to another transient benefit relationship does not allow a government's reputation to support borrowing. It is easy to construct other examples, like the protection of a given stock of intellectual property rights or building a single space station, that work in a similar fashion. A common characteristic of such examples is that the benefits from behaving well in the relationship are transient in the sense that the value of maintaining a good relationship goes to zero in finite time. 


\section{B. Adding an Enduring Benefit Relationship}

Consider adding to the Section 1 model a relationship with enduring benefits. In such a relationship the discounted value of benefits from behaving well from any point in time onwards never goes to zero. The simplest example of such a relationship is a repeated relationship in which the per period benefits are constant. More elaborate examples would include relationships with physical state variables. We illustrate how differently spillovers to enduring benefit relationships work by considering a simple repeated relationship.

Consider adding a labor relationship to the debt model. This labor relationship emanates from a project which is available in each period. If the number of workers hired is $N_{t}$, the project's output is $\mathrm{AN}_{\mathrm{l}}$. The project has a maximal size $\mathrm{N}$. (The assumption that the labor project has the same productivity as the debt project is for notational simplicity only.) The economy has a large number of domestic agents who have the specialized skills the government needs to run the project. Each of these workers is risk neutral and has an alternative employment opportunity that earns a worker $\omega$ units with certainty in each period. We assume that

\section{(2.1) $\beta \mathrm{A} \geq \omega$.}

We will model the government as maximizing its utility, subject to its resource constraints. With a little more notation, we could reinterpret the model as one in which the government maximizes the welfare of its citizens, provides public goods by using specialized resources, and taxes in a distorting way.

If there were full commitment, the equilibrium would be as follows: In period 0 , the government would take a loan of 1 from the bankers and invest it. It would hire $\mathrm{N}$ workers at wage $\omega$, pay them $\omega N$, and consume output net of repayments, namely, $(A-\omega) N$. In any period $t$ after that, it would take a new loan of 1 from the banker, invest it, and hire $\mathrm{N}$ workers at wage $\omega$. It 
would then repay the bankers $\rho$ for the old loan from period $t-1$, pay the workers $\omega N$, and consume the output net of repayments, namely, $A-\rho+(A-\omega) N$.

Consider the model without commitment. The timing of the model is the same as before, with these additions. In the beginning of each period, each of the large number of workers offers an employment schedule. Each worker $i$ offers to supply $n_{t}(i, w)$ units of labor to the government for a promise of $w_{t}$ units of pay, where $n_{t}$ is either zero or one. Confronted with a continuum of such wage schedules, all of which are identical, the government announces some particular wage $\mathrm{w}_{\mathrm{t}}$ together with an employment cap $N_{t}$. At the end-of-period $t$ when the output of the two projects are realized, the government decides whether or not to honor its contracts with the bankers and the workers. We let $\mathrm{z}_{\mathrm{t}}^{\mathrm{n}}=1$ and $z_{\mathrm{t}}^{\mathrm{b}}=1$ correspond to honoring the debt and labor contracts. The constraints faced by the government are

$$
z_{t}^{b}\left(1+r_{t}\right) b_{t}+z_{t}^{n} w_{t} N_{t} \leq A x_{t}+A N_{t}
$$

together with

$$
c_{t}+x_{t+1}-b_{t+t}=A_{t} x_{t}+A N_{t}-z_{t}^{b}\left(1+r_{t}\right) b_{t}-z_{t}^{n} w_{t} N_{t}
$$

and

(2.4) $\mathbf{x}_{t+1} \leq 1$ and $N_{t} \leq N$.

In (2.3) we have assumed that the number of workers is $\mathrm{N}_{\mathrm{t}}$.

Consider strategies in which misbehavior by the government in the debt relationship spills over to the labor relationship and vice versa. Specifically, suppose that the bankers' and workers' strategies specify that if the government ever breaks either the debt contract or the labor contract, they will never trust it again: bankers will never lend to it and workers will never work for it. We will show that with such a spillover positive borrowing can be supported in equilibrium. Indeed, if the government is sufficiently patient, the full commitment allocations can be supported. 
More formally, let the bankers' strategies at time $t$ specify that for histories of the game with no previous default, namely, $z_{s}^{b}=z_{s}^{\mathfrak{n}}=1$ for all $s<t$, then

$$
S_{t}=\left\{\left(r_{t}, b_{t}\right) \mid 1+r_{t}=\rho, b_{t} \leq 1\right\}
$$

That is, the bankers will lend at rate $\rho$ any amount up to one. For any history in which there has been a default $S_{t}=\left\{\left(r_{t}, b_{t}\right) \mid 1+r_{t}=1, b_{t} \leq 0\right\}$, and thus bankers do not lend. Let the workers' strategies specify that for histories with no previous default $n_{\mathrm{l}}\left(\mathrm{i}, \mathrm{w}_{\mathrm{l}}\right)=1$ if $\mathrm{w}_{\mathrm{t}} \geq \omega$, and zero otherwise. For any history in which there has been a default $n_{t}\left(i, w_{t}\right)=0$. The government's strategy specifies its full commitment allocations if it never defaulted in the past. If it has defaulted the government's strategies specify that it self-finance the investment project, borrows nothing and pays the workers nothing. Call these strategies the spillover strategies. We then have

Proposition 3. In an economy with debt and labor relationships there exists a $\underline{\beta} \in(0,1)$ such that for all $\beta \in[\beta, 1]$ the full commitment allocations are supportable as equilibrium outcomes.

Proof. Consider the spillover strategies defined above. Consider first histories in which there have been no defaults before time t. It is optimal for the bankers to lend 1 and the workers to work if $w_{t} \geq \omega$. It is optimal for the government to borrow 1 , fully fund the investment project, offer a wage of $\omega$, and an employment cap of $N$. Consider now the decision of whether to default. If it defaults on both contracts, the government saves the current payments to bankers and workers, $\rho+$ $\omega N$. However, it loses the surplus from the labor project, $(A-\omega) N$, from $t+1$ onwards. Thus, sticking with full commitment is at least as good as the deviation if

(2.5) $\rho+\omega \mathrm{N} \leq \frac{\beta(\mathrm{A}-\omega) \mathrm{N}}{1-\beta}$ 
As $\beta$ increases to 1 the left-hand side monotonically decreases to $1+\omega \mathrm{N}($ since $\rho=1 / \beta)$ while the right-hand side monotonically increases to infinity. Thus, there is some $\underline{\beta} \in(0,1)$ such that $(2.5)$ holds for all $\beta \in(\beta, 1)$.

For histories after deviations, the strategies are clearly optimal. Thus, the above strategies constitute a perfect equilibrium if $\beta \in[\underline{\beta}, 1]$.

So far we have investigated one particular type of trigger strategies in which there is spillover across the two types of relationships. Of course, there are many other types of strategies without such a spillover. In particular, consider strategies in which misbehavior in one relationship only affects the actions of agents in that relationship and doesn't spill over to the other relationships. Specifically, suppose that workers will continue to work as long as the government doesn't default on the labor contract and that bankers will continue to lend as long as the government doesn't default on its debt contract. These nonspillover strategies can clearly support an equilibrium with workers working positive amounts, but they can't support any positive borrowing-for the same reasons as before.

\section{Reputation Spillover Across Relationships in a Finite Horizon}

We consider now an incomplete information reputation model. It is easy to show that if there is a single debt relationship or a spillover to another debt relationship, reputation can support, effectively, zero debt. (For details, see the working paper version of this paper.) It's more relevant when thinking about applying our model of sovereign debt to actual economies to show that even with a finitely lived government spillover to a relationship with enduring benefits can support debt. Moreover, in our setup these spillovers must occur. To do so we add incomplete information to a finite-horizon version of the model with debt and labor relationships. We will compute the unique equilibrium using the standard backward induction arguments of Kreps-Wilson and Milgrom-Roberts. 
We then show that the natural limit of both the equilibrium strategies and the equilibrium outcomes are the spillover strategies used in Proposition 2. We think of this section as exploring what type of stories one must tell in order for it to be natural for such spillovers to occur.

Consider the following version of the reputation model. It has two types of government: a normal government and an honest government. The normal government is risk neutral and discounts the future at rate $\beta$. The honest government evaluates consumption streams the same way the normal government does, but the honest government also assigns a large disutility to breaking any contract it has signed. ${ }^{3}$ In particular, we can write the preferences of the honest government as

$$
\sum_{\mathfrak{t}=0}^{T} \beta^{\mathfrak{t}}\left[c_{\mathfrak{t}}-\left(1-z_{\mathfrak{t}}^{b}\right) M^{b}-\left(1-z_{t}^{n}\right) M^{n}\right]
$$

where $\mathrm{M}^{\mathrm{b}}$ and $\mathrm{M}^{\mathrm{n}}$ are large positive numbers. (Recall that $\mathrm{z}_{\mathrm{t}}^{\mathrm{b}}=1$ and $\mathrm{z}_{\mathrm{t}}^{\mathrm{n}}=1$ correspond to repayment of the debt, and labor projects and $\mathrm{z}_{\mathrm{t}}^{\mathrm{b}}=0$ and $\mathrm{z}_{\mathrm{t}}^{\mathrm{n}}=0$ correspond to default on these projects.) The type of the government is private information. Bankers hold subjective beliefs about what type the government is, and they update these beliefs after seeing the actions of the government.

We will consider a Bayesian equilibrium for this model. It should be clear that in any such equilibrium the honest government will honor all debt and labor contracts if $\mathrm{M}^{\mathrm{b}}$ and $\mathrm{M}^{\mathrm{n}}$ are sufficiently large, which we will henceforth assume to be the case. Thus, if a private agent, either a banker or a worker, sees the government break either type of contract, the agent will know for sure that the government is not honest. A simple backward induction argument implies that workers will never work for, or bankers lend to, a government that they know is not honest. Hence, the normal government will either honor both contracts or break both, since breaking either one causes the government to lose its reputation. Thus, the reputation from the trust involved in the debt relationship spills over to the trust involved in the labor relationship and vice versa. 
One way to analyze the model's implications for government borrowing is to compute the equilibrium directly by backward induction. However, we find it more convenient to develop some simple properties of the equilibrium indirectly. To do that, we first backtrack a little: we consider a model that has only a labor project and develop an expression for the value of reputation in the labor relationship alone. We then consider the model with both the debt and labor relationships. We use the result that breaking trust in the debt relationship spills over into the labor relationship to show how the full commitment level of debt can be supported.

Consider the model in which we set $x_{1}=b_{t}=0$ for all $t$. In the Bayesian equilibrium that we consider the workers' beliefs about the government are summarized by a conditional probability that the government is honest. We denote this conditional probability at $t$ by $\mathrm{p}_{\mathrm{t}}$ and call it the reputation of the government. In this equilibrium, the history of past events at the beginning of period $t$ is summarized by the conditional probability $\mathrm{p}_{\mathrm{t}}$. The strategies of agents are allowed to depend on $\mathrm{p}_{t}$, together with the actions that have already occurred within the period. Thus, the work decision of a worker can be written as $n_{t}\left(i, w_{t}, p_{t}\right)$. The model's interesting equilibria turn out to involve the government randomizing, or mixing, over whether to repay or not. Let $\sigma_{\mathrm{t}}$ denote the probability that the government repays. The equilibrium we compute has two requirements: At every possible state, each agent acts optimally, given the strategies and beliefs of other agents, and beliefs are updated according to Bayes' rule wherever possible. Since the honest government never defaults, Bayes' rule implies that the probability that the government is honest at $t+1$, conditional on repayment at $\mathrm{t}$ (and all previous periods), is

(3.1) $\mathrm{p}_{\mathrm{t}+1}=\frac{\mathrm{p}_{\mathrm{t}}}{\mathrm{p}_{\mathrm{t}}+\left(1-\mathrm{p}_{\mathrm{t}}\right) \sigma_{\mathrm{t}}}$. 
In each period $t$, each of the $N$ workers will supply one unit of labor if the expected wage is greater than or equal to $\omega$. If the honest government honors its contract and the normal government repays with probability $\sigma_{t}$, then at an offered wage of

(3.2) $\quad \mathrm{w}_{\mathrm{t}}=\frac{\omega}{\mathrm{p}_{\mathrm{t}}+\left(1-\mathrm{p}_{\mathrm{v}}\right) \sigma_{\mathrm{t}}}$

the workers will receive an expected wage of $\omega$. Hiring workers will only be profitable for the honest government if the wage rate is less than the return on the project, that is,

(3.3) $w_{t} \leq A$.

Backward induction in this model works exactly as it does in the standard Kreps-Wilson (1982) and Milgrom-Roberts (1982) models of the chain store paradox. Solving backward to period zero gives the following value function:

$$
\mathrm{V}_{0}\left(\mathrm{p}_{0}, \mathrm{~T}\right)=\left\{\begin{array}{cc}
\sum_{\mathrm{s}=0}^{\mathrm{T}-1} \beta^{\mathrm{s}}(\mathrm{A}-\omega) \mathrm{N}+\beta^{\mathrm{T}} \mathrm{AN} & \text { if } \omega / \mathrm{A} \leq \mathrm{p}_{0} \leq 1 \\
\sum_{s=0}^{\mathrm{T}-2} \beta^{\mathrm{S}}(\mathrm{A}-\omega) \mathrm{N}+\beta^{\mathrm{T}-1} \mathrm{AN} & \text { if }(\omega / \mathrm{A})^{2} \leq \mathrm{P}_{0}<\omega / \mathrm{A} \\
\vdots & \vdots \\
(\mathrm{A}-\omega) \mathrm{N}+\beta A N & \text { if }(\omega / \mathrm{A})^{\mathrm{T}} \leq \mathrm{p}_{0}<(\omega / \mathrm{A})^{\mathrm{T}-1} \\
\mathrm{AN} & \text { if }(\omega / \mathrm{A})^{\mathrm{T}+1} \leq \mathrm{p}_{0}<(\omega / \mathrm{A})^{\mathrm{T}} \\
& \text { if } \mathrm{p}_{0}<(\omega / \mathrm{A})^{\mathrm{T}+1}
\end{array}\right\}
$$

The value function corresponds to the following equilibrium behavior. In the lowest region, defined by $p_{0} \leq(\omega / A)^{T+1}$, there is no mixing probability that is both high enough to give a wage $w_{0}<A$ and low enough to push up next period's prior into the next highest region. Hence, workers do not work at period zero. Workers do not revise their priors, and then $p_{1}=p_{0}$ and the workers do not work at period 1 , and so on. The value of utility is thus zero. In the next highest region, with $(\omega / \mathrm{A})^{\mathrm{T}+1} \leq \mathrm{p}_{0}<(\omega / \mathrm{A})^{\mathrm{T}}$, workers work, and the government is just indifferent between currently 
defaulting and repaying. Thus, the value of utility is AN. In the next region, with $(\omega / A)^{T} \leq p_{0}<$ $(\omega / \mathrm{A})^{\mathrm{T}+1}$, the government strictly prefers to repay this period and will start mixing the next period. Thus, today it gets $(\mathrm{A}-\omega) \mathrm{N}$ units of consumption, from tomorrow on the value of its utility is AN, and its total utility is $(\mathrm{A}-\omega) \mathrm{N}+\beta \mathrm{AN}$. For the next highest region, the government strictly prefers to repay for two periods and then starts mixing, which gives it a total utility of $(\mathrm{A}-\omega) \mathrm{N}+$ $\beta(\mathrm{A}-\omega) \mathrm{N}+\beta^{2} \mathrm{AN}$, and so on.

Consider now the equilibrium behavior for a fixed prior $\mathrm{p}_{0}$ as the time horizon lengthens. Suppose $\mathrm{p}_{0}$ is such that

$$
(\omega / A)^{k+1} \leq p_{0}<(\omega / A)^{k}
$$

Then the government will honor its contracts for sure in the first $T-\mathbf{k}$ periods. In periods $\mathrm{T}-\mathrm{k}+1$ through period $\mathrm{T}-1$, it will mix, and in period $\mathrm{T}$, it will default. As $\mathrm{T}$ gets longer, so does the length of time that the government repays for sure, and in the limit the government never defaults.

There is a feature of this equilibrium which we will use later. Given any initial prior $p_{0}>0$, let $k\left(p_{0}\right)$ be the integer such that (3.5) holds. Thus, in period $T-k\left(p_{0}\right)$ the government is just indifferent between defaulting and repaying, and the value of either is AN. One period earlier, at $T-k\left(p_{0}\right)-1$, the value of repaying is $(A-\omega) N+\beta A N$ or

$$
\mathrm{AN}+(\beta \mathrm{A}-\omega) \mathrm{N}
$$

By assumption $\beta \mathrm{A}>1>\omega$, so that in moving back one period the value of repaying strictly increases while the value of defaulting remains fixed at AN. Thus, there is a strictly positive gap of $(\beta \mathrm{A}-\omega) \mathrm{N}$ between these values. Continuing in this manner it is clear that from (3.4) that $\mathrm{j}$ periods before $T-k\left(p_{0}\right)$ the value of repaying can be rewritten as 
(3.7) $\mathrm{AN}+\frac{\left(1-\beta^{\mathrm{j}}\right)}{1-\beta}(\beta \mathrm{A}-\omega) \mathrm{N}$

while the value of defaulting is simply AN. Thus the gap between the value of repaying and the value of defaulting monotonically increases as we move back in time from $T-k\left(p_{0}\right)$.

We will construct borrowing, investing, and repaying allocations which coincide with the full commitment levels for all but a fixed finite number of periods at the end of the game. Given some $k^{\prime}$, let these allocations specify: follow the full commitment allocations before $T-k^{\prime}$; at $T-k^{\prime}$, switch to self-financing the investment project. More precisely, given $k^{\prime}$, let these allocations specify borrow 1 , invest 1 , and repay $\rho$ for $t<T-k^{\prime}$. For $t=T-k^{\prime}$, borrow 0 , invest 1 , and repay $\rho$. For $\mathrm{t}>\mathrm{T}-\mathrm{k}^{\prime}$, borrow 0 , invest 1 , repay 0 , and save 1 .

The question of interest is, For what $\mathrm{k}^{\prime}$ can these allocations be supported in the reputation model with spillovers? To compute this number, ignore spillovers for a moment and consider only the direct costs and benefits of defaulting on the debt. At any date $t \leq T-k^{\prime}$, the net benefits of defaulting on the debt are simply the saving of funds used to repay the loan, namely $\rho$. For $\mathbf{t}>$ $\mathbf{T}-\mathbf{k}^{\prime}$ there are no loans, so the net benefits of defaulting are zero. Now add back in the spillover effects. For some given prior $p_{0}$ if we set $k^{\prime}=k\left(p_{0}\right)+1$, the difference between the value of honoring both debt and labor contracts and defaulting at date $T-k^{\prime}$ is $(\beta \mathrm{A}-\omega) \mathrm{N}-\rho$. At any date before this the net benefits to defaulting on the debt are the same, namely, $\rho$, while the gap between repaying and defaulting on the labor project increases. At any later date after this there is no debt, so the net benefits of defaulting on it are obviously zero. Thus, if

(3.8) $\rho<(\beta \mathrm{A}-\omega) \mathrm{N}$

then it is possible to support the full commitment allocations from date 0 through date $T-k^{\prime}$ with $\mathbf{k}^{\prime}=\mathbf{k}\left(\mathrm{p}_{0}\right)+1$. More generally for any given $\beta$, let $\mathrm{j}(\beta)$ be the first integer such that the gap 
between the net benefits of defaulting on the debt are smaller than the net gains from repaying the workers, namely

(3.9) $\rho<\frac{\left(1-\beta^{j}\right)}{1-\beta}(\beta \mathrm{A}-\omega) \mathrm{N}$.

If we let $\mathbf{k}^{\prime}=\mathrm{k}\left(\mathrm{p}_{0}\right)+\mathrm{j}(\beta)$, then using the same reasoning as before we can support the full commitment allocations up to period $T-k^{\prime}$.

Next consider the strategies in the equilibrium. For computational reasons we have found it convenient to express these strategies as functions of the state variable $\mathrm{p}_{l}$. Of course, the more general way of defining strategies is to define them as functions of the entire history of past actions of the players. It is obvious that for $t<T-\mathbf{k}^{\prime}$ the strategies of the normal government, the bankers, and the workers are simply the truncation of the spillover strategies. In particular, if the government has never defaulted on either contract, the lenders and workers continue with their full commitment actions while if it has defaulted bankers lend and the workers do not work. (Of course, for $\mathrm{t} \geq \mathrm{T}-\mathrm{k}^{\prime}$ these strategies do not coincide with the truncation of the infinite horizon spillover strategies and, moreover, they are somewhat complicated to write down as functions of the history.) We summarize our discussion with

Proposition 4. There exists a $\beta \in(0,1)$ such that for all $\beta \in(\beta, 1)$ the equilibrium allocations coincide with those under full commitment from period 0 through period $T-k^{\prime}$, where $k^{\prime}=k\left(p_{0}\right)$ $+\mathrm{j}(\underline{\beta})$. Moreover, during these same periods the strategies of the normal government, the bankers, and the workers coincide with the truncation of the infinite spillover strategies of Proposition 2.

Now there is a natural sense in which both the equilibrium allocations and strategies converge to those of Proposition 2. We have 
Corollary 1. Consider a sequence of economies in which $\mathrm{T}$ converges to infinity. Given the $\underline{\underline{B}}$ of Proposition 3, for any $\beta \in(\beta, 1)$ the equilibrium allocations and strategies converge to those of Proposition 2. Moreover, these limiting strategies are themselves an equilibrium of the natural infinite horizon game.

To be precise, the infinite horizon game of Section 2 must be trivially modified to include the honest government. Clearly, the limiting strategies for the normal government, the lenders and workers, namely, the spillover strategies, plus the limiting strategies of the honest government, constitute an equilibrium of this modified infinite horizon game. Now the limiting economy discussed above is an infinite horizon incomplete information economy with probability $\mathrm{p}_{0}$ of an honest government. In such a limiting economy there are, of course, a large set of other trigger-type equilibrium. Here we have shown that the natural limit of our finite horizon economy goes smoothly to one member of this set, namely, the one with spillover strategies.

Finally, we consider a sequence of economies in which the amount of incomplete information is converging to zero as the horizon length grows. To that end, consider the following:

Condition 1 . The sequence of priors, $\mathrm{p}(\mathrm{T})$, satisfy

(3.11) $(\rho / \mathrm{A})^{\mathrm{k}(\mathrm{T})+1} \leq \mathrm{p}_{0}(\mathrm{~T})<(\rho / \mathrm{A})^{\mathrm{k}(\mathrm{T})}$

where (i) $k(T)$ converges monotonically to infinity as $T$ does and (ii) $T-k(T)$ converges to infinity. Since $\rho / A<1$, clearly $p_{0}(T)$ monotonically converges to zero as $T$ converges to infinity. Now consider a sequence of economies indexed by $\mathrm{T}$ and $\mathrm{p}_{0}(\mathrm{~T})$. Along such a sequence the importance of the honest government is monotonically declining to zero. Notice that in a sense the prior is shrinking to zero more slowly then the horizon length is growing to infinity.

Consider a sequence of economies indexed by $T$ and $p_{0}(T)$ where $p_{0}(T)$ satisfies Condition 1. Let $\underline{\beta}$ be such that $(3.10)$ is satisfied for some finite $j(\underline{\beta})$. In this setup, the sequence of finite horizon 
economies with incomplete information converge in a natural sense in the space of economies to the infinite horizon economy with complete information. Using (3.4) and the above analysis, one can show that the equilibrium value of utility converges to the full commitment level. Moreover, there is a natural sense in which the equilibrium strategies converge to the infinite horizon spillover strategies. Finally, these limiting strategies themselves constitute an equilibrium of the limiting economy, namely, the infinite horizon economy with complete information.

\section{Scope and Limitations of the Analysis}

The main point of the paper is that if a government always has an adequate means to save, reputation can support debt only if there is reputation spillover to a nondebt relationship with enduring benefits. We set up the Bayesian model to capture the idea that an agents behavior in one type of relationship may provide information as to their behavior in other types of relationships. The model captures this idea in a stark fashion: if the government does not honor contracts in one relationship, then all agents know for sure that it will not honor them in any other relationship.

Now if we amend the model so as to weaken the connection between behavior across relationships then the reputation spillover diminishes and so does the mutually reinforcing effects of different relationships. To see this, suppose that we weaken the correlation of honest behavior across relationships by adding to the model types of governments that are honest only in the labor relationship or types that are honest only in the debt relationship. In such a model, if workers see the government default on a debt they know the government is not honest in the debt relationship, but they don't know whether the government is normal or simply honest only in the labor relationship. If the prior on the type of government which is honest only in the labor relationship is high enough that workers will work based on that prior alone, then the spillover across relationships disappears: a normal government would find it optimal to default, and the lenders would 
realize this and not lend. Of course, if the prior on the honest-in-labor government were smaller than this critical level, but the sum of the priors on the honest-in-labor and honest-in-both were higher, then there would be a spillover effect. This result is intuitive: the only way misbehavior in a relationship with transient benefits can have large costs is when this misbehavior has enough information content that agents in relationships with enduring benefits are put off by it.

It is interesting to contrast how this model works when more types of agents are added with the standard reputation model of Kreps-Wilson and Milgrom-Roberts. If more types of incumbents are added in addition to the tough incumbent in the chain store model, basically the same equilibrium goes through. Indeed, Fudenberg and Levine (1989) show that regardless of the number and probabilities of types that are added, as long as the normal type and the tough type have strictly positive priors then any equilibrium has payoffs which are close, in the sense of average payoffs, to the full commitment payoffs. (For a detailed discussion of the general results in this area see Fudenberg and Levine 1989.)

In Section II we showed that adding another transient benefit relationship did not lead to mutually reinforcing effects but that adding an enduring benefit relationship did. There is a connection between this type of result and the results in Fudenburg and Kreps (1987), who investigate various versions of a concession game. They show that multiple relationships may or may not be mutually reinforcing, depending on what they assume about whether entrants that concede can later reenter. If such entrants can reenter, then multiple relationships are mutually reinforcing while if they cannot then the relationships are not. In Fudenburg and Krep's model, there is a sense in which each relationship has enduring benefits if entrants can reenter, while it has only transient benefits if they cannot.

There is also a connection between our results and the results in the I.O. literature by Bernheim and Whinsten (1990) on how multimarket contact between oligopolistic firms may help 
facilitate collusive behavior. Bernheim and Whinsten show in an infinite horizon model of repeated duoploy that replicating the oligopolistic interaction does not change the set of perfect equilibria. This is analogous to our result that adding another debt relationship does not change the set of perfect equilibria. They also show that if the second type of market interaction is not symmetric then multimarket contact may facilitate collusion in the sense that for a fixed discount factor the set of perfect equilibria expands. Of course in our terminology all of the relationships Bernheim and Whinsten consider are enduring (since they are repeated) and so the folk theorem holds for the original single market contact models to begin with. In particular, even with only the original single relationship the full commitment outcome can be supported for large enough discount factors. In our dynamic models with state variables, like debt or oil, the folk theorems do not hold for the original model, and it is only when there is spillover to an enduring benefit relationship that good outcomes can be supported.

We turn next to our notions of enduring and transient benefits. In the infinite horizon complete information game with a single debt relationship, the value of the relationship depended on the value of outstanding debt. Along any outcome path once the government has received the largest loan in present value terms it had no need for the lenders. We termed such a relationship one with transient benefits because its benefits only lasted up until the point at which the government received all it wanted from the lenders. In the model this occurred within finite time. Likewise, in the oil example the potential benefits from cooperative behavior lasted only until the oil stock ran out. In the model this also occurred within finite time. In contrast, in the infinite horizon game with a repeated labor relationship, no matter what happened in the past, the government never receives all its wants from the workers, instead it always needs them in the future. We termed this type of relationship one with enduring benefits because the value of the relationship stays high forever. 
Now in any finite horizon version of the complete information models we consider backward induction unwinds all equilibria other than autarky. There are, of course, other models which have relationships that give rise to multiple equilibria even in finite horizon. (For some work on characterizing equilibria in such models see Benoit and Krishna (1980)). Spillovers from such relationships can potentially support good outcomes in the debt relationship. To see this consider a three period repeated coordination game with a good equilibrium and a bad equilibrium at each stage. Strategies which specify that misbehavior in the debt relationship lead to playing the bad equilibrium in the third period can potentially support the repayment of the interest plus principal on full commitment level of debt in the second period. We do not consider such relationships both because they do not square well with the type of stories Bulow and Rogoff told when forming their conjecture and because we do not find them very interesting in their own right.

In our finite horizon models with incomplete information, backward induction does not unwind all equilibria other than autarky. In such models a more subtle distinction between transient benefit type relationships and enduring benefit type relationships must be made. In a repeated relationship, like the labor-relationship, the value of maintaining a good reputation in the relationship in any one period is constant, regardless of the history of play. Thus as we move back from the end of the game the value of the relationship grows by a constant amount, in discounted terms, every time a period is added. After enough periods, the value of the relationship outweighs the benefits of default, and good outcomes can be supported. In the debt relationship, the value of maintaining it depends crucially on the level of the state variables, the new output. Bankers realize that as the size of the new output approaches one, the value of the relationship approaches zero for the normal government. Because of this fact bankers lend very little in the beginning and lend larger amounts over time only as they become more convinced that the government is honest. This allows the government to establish a reputation without giving it enough funds so that it can become self- 
sufficient. For low values of the prior this means that the government doesn't do much better than in autarky. (For details, see Cole and Kehoe 1991.)

\section{Conclusion}

We have examined the Bulow Rogoff conjecture that since actual economies are involved in a myriad of relationships, general reputation models with potential spillovers to other relationships may be able to support good outcomes. We found that in a class of models this conjecture does not hold if reputation spills over to other relationships with only transient benefits, but it does when reputation spills over to a relationship with enduring benefits.

The idea that an agent's reputation in one relationship may spill over into other relationships is certainly not new. However, in most of literature the spillover is such that actions of agents in one arena of behavior affect reputation in that arena only. In the debt literature, for example, if a government defaults it ruins its reputation in the debt arena; in the industrial organization literature on entry deterrence, if an incumbent doesn't fight entry, it ruins the incumbent's reputation in the entry deterrence arena. Here we have shown that when spillovers stay within the debt arena, reputation cannot support lending. For that, a government's actions in the debt arena must spill over to a different type of arena, such as labor relationships. Viewed this way, the benefits of maintaining a good relationship in one arena cannot be calculated simply by looking at that arena alone. Instead, account must be taken of the ramifications in a variety of other arenas, which, at least on the surface, may not seem to be directly connected to the arena in which the misbehavior originates.

This basic idea can be applied in many contexts. It might explain why countries honor some commitments, like treaties, when a narrow cost-benefit analysis would recommend breaking them. Consider, for example, a fishing treaty between the United States and Canada. Suppose that at the time the treaty was signed it seemed like a good idea, but later developments reveal that the treaty 
is costing the United States a lot. Nonetheless, the United States might honor the treaty because breaking it would damage its reputation with Canada in other relationships that involve trust. Moreover, breaking that treaty might cause a negative reputation spillover with, say, the Japanese in a completely different arena that involves a trust relationship, such as a mutual defense pact. 


\section{Footnotes}

${ }^{1}$ For some interesting nonreputation based models of debt and default, see Guillermo Calvo (1988), Bulow and Rogoff (1989a), and Raquel Fernandez and Robert Rosenthal (1990).

${ }^{2}$ For some other incomplete information models of debt, see Eaton (1992) and Fernandez and Kaaret (1993).

${ }^{3}$ Eaton (1992), following Diamond (1989), considers a reputation model in which there are two types of borrowers: "good" borrowers for whom the lender can costless "destroy" output if they default and "normal" borrowers for whom the lender cannot. Eaton, however, assumes there is no way to save, so the model does not satisfy the Bulow and Rogoff assumption on institutions. 


\section{Appendix}

Proof of Proposition 1. Consider an equilibrium outcome. In any equilibrium bankers break even so

(1.8) $\left[\left(1+r_{t}\right) z_{t}-\rho\right] b_{t}=0$

If there are any loans made, it follows that the gross interest rate is $\rho$, that is, if $z_{t}=1$ and $b_{t} \neq 0$ then $1+r_{t}=\rho$. If $z_{t}=0$, then no loans are made, so $b_{t} \leq 0$. Clearly $b_{t}$ cannot be greater than or equal to 1 in any equilibrium. If it were then the government would certainly prefer to deviate by defaulting on the amount owed, $\rho \mathrm{b}_{\mathrm{t}}$, and then consuming $\rho \mathrm{b}_{\mathrm{t}}-1$ in extra consumption at date $\mathrm{t}$. In all future periods it would fund the project by investing 1 and it would consume $A-1$ in each period. Since $b_{t}$ is bounded in equilibrium it follows that

(1.9) $\lim _{t \rightarrow \infty} \beta^{t} b_{t}=0$

Next we show that $b_{t}$ cannot be any strictly positive number between 0 and 1 . By way of contradiction, suppose at some date, say date $v$, that $b_{v}>0$. Let

(1.10) $\beta^{r} b_{r}=\max _{t} \beta^{t} b_{t}$.

Thus $r$ is the date at which the present value of borrowing is the largest. Clearly $r$ is finite since $b_{\mathfrak{t}} \leq 1$ for all $t$. If there are multiple dates which satisfy (1.11) let $r$ be the largest such date. Consider, for now, deviating at date $r$ by defaulting at date $r$ and then continuing with the original consumption and investment levels. To see that this is feasible first note that the original debt sequence must satisfy

(1.11) $\beta^{t} b_{t}=\sum_{s=t}^{\infty} \beta^{s+1}\left(A x_{s}-c_{s}\right)$

where we have obtained this by iterating on (1.7) and using (1.8) and (1.9) gives that for any t. 
Under our deviation the new debt sequence, denoted by $\hat{b}_{t}$, satisfies for $t \geq r$,

(1.12) $\beta^{t} \hat{b}_{t}=\sum_{s=t}^{\infty} \beta^{s+1}\left(A_{s}-c_{s}\right)-\beta^{r} b_{r}$.

Since $\beta^{t} b_{t}<\beta^{r} b_{r}$ for all $t>r$, it follows that $\hat{b}_{t}$ is nonpositive. Under this deviation the government never borrows again from the bankers but rather self-finances the investment and consumption stream by saving. Note also that since under the original allocation equations (1.9) and (1.10) hold, it follows that

(1.13) $\lim _{\mathrm{t} \rightarrow \infty} \beta^{t} \hat{b}_{\mathrm{t}}=-\beta^{\mathrm{r}} \mathrm{b}_{\mathrm{r}}$.

Clearly, there is some sufficiently large date $\mathrm{T}$ such that it is possible to increase consumption at $\mathrm{T}$ and still have the new debt sequence be nonpositive. Since this deviation is preferred to the conjectured outcome no such equilibrium can exist. 
References

Alexander, Lewis S. 1987. The legal consequences of sovereign default. Manuscript, Washington:

Federal Reserve Board. International Borrowing: Negotiation and Renegotiation, ed. Daniel D. Bradlow and Willy Jourdan. Washington: International Law Institute, 1984.

Atkeson, Andrew. 1991. International lending with moral hazard and risk of repudiation. Econometrica 59, (July): 1069-90.

Backus, David, and Driffill, John. 1985. Inflation and reputation. American Economic Review 75, (June): $530-38$.

Barro, Robert J. 1986. Reputation in a model of monetary policy with incomplete information. Journal of Monetary Economics 17, (January): 3-20.

Benoit, J.P., and Krishna, V. 1985. Finitely repeated games. Econometrica 53: 908-904.

Bernheim, B., Douglas and Whinsten, Michael D. 1990. Multinational contact and collusive behavior. RAND Journal of Economics 21, No. 1.

Bulow, Jeremy, and Rogoff, Kenneth. 1989a. A constant recontracting model of sovereign debt. Journal of Political Economy 97, (February): 155-78.

- 1989b. Sovereign debt: Is to forgive to forget? American Economic Review 79, (March): 43-50.

Calvo, Guillermo A. 1988. Servicing the public debt: The role of expectations. American Economic Review 78, (December): 647-61.

Cole, Harold L.; Dow, James; and English, William B. 1989. Default, settlement and signaling: Lending resumption in a reputation model of sovereign debt. CARESS Working Paper 89-26. University of Pennsylvania. 
Cole, Harold L., and Kehoe, Patrick J. 1992. The role of institutions in reputation models of sovereign debt. Research Department Working paper. Federal Reserve Bank of Minneapolis.

Eaton, Jonathan. 1992. Sovereign debt, reputation, and credit terms. Manuscript. Boston University.

Eaton, Jonathan, and Gersovitz, Mark. 1981. Debt with potential repudiation: Theoretical and empirical analysis. Review of Economic Studies 48, (April): 289-309.

Fernandez, Raquel, and Kaaret, David. 1992. Bank heterogeneity, reputation, and debt renegotiz tion. International Economic Review 33, No. 1. : 61-78.

Fernandez, Raquel, and Rosenthal, Robert W. 1990. Strategic models of sovereign-debt renegotiations. Review of Economic Studies 57, (July): 331-49.

Fudenberg, Drew, and Kreps, David M. 1987. Reputation in the simultaneous play of multiple opponents. Review of Economic Studies 54, (October): 541-68.

Fudenberg, Drew, and Levine, David K. 1989. Reputation and equilibrium selection in games with a patient player. Econometrica 57 , (July): 759-88.

. Maintaining a reputation when strategies are imperfectly observed. Review of Economic Studies, forthcoming.

Grossman, Herschel I., and Van Huyck, John B. 1988. Sovereign debt as a contingent claim: Excusable default, repudiation, and reputation. American Economic Review 78, (December): $1088-97$.

Kletzer, Kenneth M., "Asymmetries of Information and LDC Borrowing With Sovereign Risk," Economic Journal 94, 1984: 287-307.

Kreps, David M., and Wilson, Robert. 1982. Reputation and imperfect information. Journal of Economic Theory 27, (August): 253-79. 
Loury, Glenn C. 1990. Tacit collusion in a dynamic duopoly with indivisible production and cumulative capacity constraints. Manuscript. Kennedy School of Government, Harvard University.

Manuelli, Rodolfo. 1986. A general equilibrium model of international credit markets. Manuscript. Stanford University.

Milgrom, Paul, and Roberts, John. 1982. Predation, reputation, and entry deterrence. Journal of Economic Theory 27, (August): 280-312

Rosenthal, Robert W. 1991. On the incentives associated with sovereign debt. Journal of International Economics 30 (1-2), (February): 167-76. 